\title{
Article Index by Subject Category
}

\section{JMCP - July/August 1995 through November/December 2002}

\section{Adherence, Compliance, and Persistence}

- Adherence, compliance, and persistence in drug therapy. 2002; May/Jun:177-78.

- Measuring adherence and persistence in drug therapy. 2002;May/Jun:204-46.

- Patient adherence with HMG reductase inhibitor therapy among users of two types of prescription services. 2002; May/Jun:186-91.

- A team approach to address antiretroviral therapy adherence barriers in a managed care organization. 2001;May/Jun:214-18.

- The Michigan pharmacists association patient persistency project. 2001;Jan/Feb:50-55.

- Evaluating medication adherence: which measure is right for your program? 2000;Nov/Dec:499-504.

- Unclaimed prescriptions requisitioned through provider order entry. 1999;Nov/Dec:498-502.

- Predicting adherence to prescription medication purchase among HMO enrollees with diabetes. 1999;Jul/Aug:336-41.

- Analyzing variations in medication compliance related to individual drug, drug class, and prescribing physician. 1999; Jan/Feb:47-51.

- A study on the characteristics of prescription transmittal processes and the effect of a patient prescription reminder system on patient compliance. 1998;Mar/Apr:174-78.

- "Abandoned prescriptions": a quantitative assessment of their cause 1995;Nov/Dec:193-99.

\section{Adverse Drug Events}

- Medical errors, adverse medical events, and PDRM. 2002;Sep/Oct: 400.

- Preventable drug-related morbidity indicators in the U.S. and U.K. 2002;Sep/Oct:372-77.

- Preventable drug-related morbidity in older adults. 1. Indicator development. 2002;Sep/Oct:365-71.

- Evaluation of resources used to treat adverse events of selective serotonin reuptake inhibitor use. 2001;Sep/Oct:402-06.

- Adverse drug events: a plea for reporting and new rules to ease the burden. 1998;Jul/Aug:364.

\section{Behavioral Health}

- Issues and trends in behavioral health and managed care. 2000;Jan/Feb:11,12,15-16.

\section{Biotechnology}

- Biotechnology and managed care. 2000;Sep/Oct:410-14

- Biotechnology as a pharmacy specialty. 1998;Sep/Oct:465,468-70

\section{Capitation Financing Methods}

- Demographics and the cost of pharmaceuticals in a private thirdparty prescription program. 2000;Sep/Oct:395-402,407-09.
- Letter: Challenges to methods used in studying capitation reimbursement. 2000;Jan/Feb:8.

- Managing pharmacy risk in physician groups. 1999; Sep/Oct:382-84

- The impact of pharmaceutical capitation to primary medical groups on the health care expenditures of Medicare HMO enrollees. 1999;Sep/Oct:414-19.

\section{Clinical Pharmacy Interventions- Quality, Service, and Cost Outcomes}

- Crossing the quality chasm-pharmacist prescribing, nontraditional interventions, and outcomes-based pharmacist reimbursement (OBPR). 2002;Sep/Oct:403-04

- Quality and cost outcomes of clinical pharmacist interventions in a capitated senior drug benefit plan. 2002;Mar/Apr:124-31.

- Determining the value of pharmacy services-the search for rigorous research designs. 2002;Mar/Apr:152-53.

- Effects of a community pharmacist-based diabetes patientmanagement program on intermediate clinical outcome measures. 2002;Jan/Feb:48-53.

- Factors affecting pharmacist consultation services in a university health insurance plan. 2002;Jan/Feb:55-56.

- Community pharmacists and diabetes health care. 2002;Jan/Feb:5657.

- Collaborating with community pharmacists to improve the quality of diabetes care in an IPA-model HMO. 2001;Jul/Aug:292-96.

- Implementation and evaluation of a pharmacist-managed diabetes service. 2000;Nov/Dec:488-93.

- Impact of a diabetes disease management clinic on the total glycosylated hemoglobin of patients with type 2 diabetes mellitus. 1999;Nov/Dec:511-15.

- Using patient expectations and satisfaction data to design a new pharmacy service model in a primary care clinic. 1997;Sep/Oct:531-40.

- AIDS enters new era with pharmacists on the front lines. 1997;Jul/ Aug:391-92,395-96.

- Outcomes management: the why, what, and how of data collection. 1997;May/Jun:345-51.

\section{Clinical Pharmacy-Patient Consultation}

- Factors affecting pharmacist consultation services in a university health insurance plan. 2002;Jan/Feb:32-40.

- Providing patient-focused care within a managed care and pharmaceutical care environment: a person/situation interactionist model for community practitioners. 2000;May/Jun:233-39.

- Counseling: where does the profession stand? 1998; Jan/Feb:78.

\section{Clinical Pharmacy—Payment for Services}

- Outcomes-based pharmacist reimbursement: Reimbursing pharmacists for cognitive services. 2002;Sep/Oct:383-91.

- Reimbursement for pharmacy cognitive services: pharmacists' assessment. 1999;Sep/Oct:420-424. 
- Mississippi Medicaid waiver breaks new ground for pharmacists. 1996;Nov/Dec:564,566.

- Cost-benefit analysis of pharmaceutical care in a Medicaid population—from a budgetary perspective. 1998; May/Jun:303-08.

- Reimbursement for pharmacy cognitive services: insurance company assessment. 1997;Jan/Feb:46-48,50-51.

- Community-based pharmacy: partnering with managed care to provide value-added services. 1996;Sep/Oct:483,487-88.

\section{Clinical Pharmacy Quality Improvement}

- A prescription for change: bridges to cross the "quality chasm." 2001; Jul/Aug:309-14.

- Designing a framework for pharmacy practice: a look at consumer reactions and expectations. 2001;May/Jun:193-200.

- The case for pharmacy report cards. 1999;May/Jun:176,17980,182

- Managing drug therapy decisions: pay me now or pay me later. 1998;May/Jun:242,245.

- Response-oriented patient evaluation survey (ROPES): an administrator's tool for identifying opportunities for service quality improvement. 1998;May/Jun:311-20.

- Performance reporting for managed care prescription programs. 1998;Mar/Apr:160-66.

- Do we measure up in reducing morbidity and mortality? 1997;Nov/Dec:651-52,654-55,658.

- Medical outcomes: creating new opportunities for pharmacy. 1997;May/Jun:289-92.

- Pharmaceutical care: needed now more than ever. 1995; Jul/Aug:2122,25 .

- Documenting indicators of pharmaceutical care in rural community pharmacies. 1996;Nov/Dec:659-66.

\section{Clinical Pharmacy Quality Improvement- Patient Safety and Prevention of ADEs}

- Quality improvement, risk management, and patient education: tools to reduce medication error. 2001;Mar/Apr:156-63.

- Adverse drug reaction tracking and management in an integrated health care system. 1997;Nov/Dec:644-47,650.

\section{Clinical Practice Guidelines (CPGs)}

- Crossing the quality chasm-incremental change through clinical practice guidelines (CPGs). 2002;Sep/Oct:400-01.

- Actual prescribing versus guidelines. 2002;Jul/Aug:297-98.

- Relationship of clinical factors to the use of Cox-2 selective NSAIDs within an arthritis population in a large HMO. 2002; Jul/Aug:252-58.

- An assessment of the effectiveness of a nonsteroidal anti-inflammatory drugs algorithm in an integrated health care system. 2001;Mar/Apr:149-55

\section{Collaboration-Pharmacists and Others}

- Rear window: actuaries and pharmacists-toward a new competency. 2001;May/June:233-37.

- Physician attitudes toward pharmacist-run anticoagulation clinics in Department of Defense Health Services Region 5. 1998;Jul/Aug:41319.

- Physician groups embrace pharmacists: collaborations that work. 1997;Sep/Oct:526-28,530.

- Blood pressure outcomes in a pharmacist-and-nurse managed hypertension clinic: a team approach. 1997;May/June:307-12.

- Pharmacy practice in the long-term care environment. 1997;Mar/Apr: 189-94.

\section{Collaboration-Pharmacy Education}

- A unique partnership: the Arkansas College of Pharmacy and the Arkansas PRO. 2002;Jan/Feb:12,14.

- Oregon State University partners with Medicaid and a managed care organization. 2001;May/June:185-86.

- The University of Colorado School of Pharmacy and the University of Colorado Health Plan forge a PBM partnership. 1998;Sep/Oct:478, 480.

- $\quad$ Rutgers opens door to managed care. 1997;Nov/Dec:717-18.

\section{Collaborative Practice-Pharmacists as Prescribers}

- Collaborative pharmacy practice: an idea whose time has come. 1999; Nov/Dec:487-88, 491.

\section{Database Analyses of Drug Utilization (see also Research Methods)}

- Oral isotretinoin: an analysis of its utilization in a managed care organization. 2002;Jul/Aug:272-77.

- Cost and utilization patterns of fentanyl transdermal system and oxycodone hydrochloride controlled-release in a California Medicaid population. 2002;Mar/Apr:132-40.

- Claims data and drawing appropriate conclusions. 2002;Mar/Apr:152.

- Administrative databases and outcomes assessment: an overview of issues and potential utility. 1999;May/June:215-22.

- Basics of managed care claims processing: from claims payment to outcomes management. 1995;Nov/Dec:200-05.

\section{Decision Support Systems (DSS)}

- Understanding decision support systems. 2002;Mar/Apr:96-101.

\section{Direct-to-Consumer Advertising (DTCA) (see also Drug Promotion and Advertising)}

- Direct-to-patient advertising (DTPA) and direct-to-consumer advertising (DTCA) of prescription drugs. 2002;Nov/Dec:521. 
- Promotion of prescription drugs to consumers: case study results. 2002;Nov/Dec:512-18.

- Responding to direct-to-consumer advertising. 2000;May/Jun:201-02.

- Direct-to-consumer advertising provides challenge to managed care. 1999;Mar/Apr:101-03,106.

- The patient as a partner in prescribing: direct-to-consumer advertising. 1998;Jan/Feb:15-16,18-19.

\section{Disease Management-ALS (Amyotrophic Lateral Sclerosis)}

- Treatment of patients with ALS: implications for the managed care pharmacist. 1996;Nov/Dec:599-604.

\section{Disease Management-Angina, CHD, and CHF}

- Congestive heart failure: a disease management approach in longterm care patients. 1999;Nov/Dec:516-20.

- Managing congestive heart failure in a Medicare risk population.1999; Jan/Feb:14-16.

- Direct medical costs of unstable angina pectoris in a defined population. 1999;Jan/Feb:39-44.

- Changing practices in home inodilator infusion therapy for advanced congestive heart failure. 1998;Jan/Feb:73-77.

\section{Disease Management-Arthritis and Joint Pain}

- Cost-effective use of Cox-2 drugs and NSAIDs. 2002;Jul/Aug:295-96.

- Relationship of clinical factors to the use of Cox-2 selective NSAIDs within an arthritis population in a large HMO. 2002;Jul/Aug:252-58.

- Economic considerations in the management of arthritis. 1999; Nov/Dec:476-78,481-82,484.

- New options in the treatment of arthritis. 1999;Sep/Oct:443-48.

- Pharmacoeconomics of NSAIDs: beyond bleeds. 1997:Jul/Aug:425-30.

\section{Disease Management—Asthma and Allergic Rhinitis}

- Costs and utilization patterns associated with persistent asthma: a comparison of Texas Medicaid patients with and without continuous inhaled corticosteroid treatment. 2001;Nov/Dec:452-59.

- An investigation of allergic rhinitis, asthma, and medication use in a privately insured population. 2001;Jul/Aug:287-91.

- Impacts of a PBM-based disease management program on asthma medication use. 2001;Nov/Dec:460-67.

- Evaluating asthma medication use before and after an acute asthmarelated event. 2001;Jul/Aug:303-08.

- A claims data analysis of patient acquisition of drug therapies for the treatment of asthma. 1999;Jul/Aug:342-46.

- Evaluating health-related quality of life in three disease management areas: asthma, diabetes, and hypertension. 1996;Jul/Aug:408-13.

- Asthma disease management: integration of DUR, case management, and performance indicators. 1996;Jan/Feb:59.

\section{Disease Management-Atopic Dermatitis}

- Prevalence and costs of atopic dermatitis. 2002;Sep/Oct:404

- The effect of atopic dermatitis on total burden of illness and quality of life on adults and children in a large managed care organization. 2002;Sep/Oct:333-42.

\section{Disease Management-Cancer}

- Oncology drugs and managed care. 1998;Jul/Aug:374-75,378,380.

\section{Disease Management-Deep Vein Thrombosis}

- Outpatient treatment of uncomplicated deep vein thrombosis: an overview of program development. 1997;Mar/Apr:170,173-74.

\section{Disease Management-Depression}

- Depression in managed care: costs of selective serotonin reuptake inhibitors. 2001;Mar/Apr:142-48.

- Documentation of indicators for antidepressant treatment and response in an HMO primary care population. 2000; Nov/Dec:494-98

- Utilization patterns of antidepressant medications in a patient population served by a primary care medical group. 1999; May/Jun:243-49.

- SSRI-to-SSRI switching and associated dosing characteristics. 1999; Mar/Apr:138-43

- The treatment of depression with newer antidepressants: pharmacology and efficacy versus clinical effectiveness. 1999;Jan/Feb:57-62.

\section{Disease Management-Diabetes (see also Clinical Pharmacy Interventions)}

- Evaluating medication use for continuous quality improvement in diabetes care. 2002;Sep/Oct:378-82.

- Importance of blood glucose monitoring to achieve short- and longterm glycemic control. 1999; Nov/Dec:543-47.

- The cost of managing diabetes mellitus: focus on the oral pharmacologic management of type 2 diabetes. 1999;Mar/Apr:113-20.

- Diabetic nephropathy prevention and the role of managed care pharmacists. 1997;Nov/Dec:682-87.

- Use of glycosylated hemoglobin testing among patients with diabetes mellitus. 1997;Nov/Dec:691-96.

- Evaluating health-related quality of life in three disease management areas: asthma, diabetes, and hypertension. 1996;Jul/Aug:408-13.

- Saving vision: an intervention for HMOs. 1996;Mar/Apr:178,180.

\section{Disease Management-Heartburn}

- Validation of a single-patient drug trial methodology for personalized management of gastroesophageal reflux disease. 2002;Nov/ Dec:459-68. 
- Cost-benefit computer modeling of helicobacter pylori testing and treatment in patients on long-term H2-blocker prophylaxis. 2000;Sep/ Oct:383-89.

- Gastroesophageal reflux disease in a managed care setting: charges by place and type of service. 1998;May/Jun:336-43.

- Defining strategies for peptic ulcer treatment: a helicobacter pylori economic-cost model. 1998;Mar/Apr:205-20.

- Gastroesophageal reflux disease in a managed care setting: professional, facility, and pharmacy charges. 1998;Jan/Feb:64-70.

- Peptic acid disorders: developing a disease management program. 1996;Sep/Oct:569-75.

- AMCP's annual meeting: controversies surrounding helicobacter pylori. 1996:Jul/Aug:377-79.

- Economic implications of self-treatment of heartburn/nonulcer dyspepsia with nonprescription famotidine in a managed care setting. 1996;May/Jun:263-71

\section{Disease Management-Hypercholesterolemia}

- Effective cholesterol management with fewer dollars. 2002;Nov/Dec: 519.

- High blood cholesterol and ATPIII: guidelines for health benefit and health care providers. 2001;Nov/Dec:482-89.

- Comparative cost-effectiveness of fluvastatin and lovastatin in patients with hypercholesterolemia. 2000;May/Jun:241-46.

- A comparison of hypercholesterolemia management in the secondary prevention of coronary heart disease by payor types: fee-for-service, Medicare, and managed care organizations. 1998;Sep/Oct:483-87.

- The cost-effectiveness impact of a preferred agent HMG-CoA reductase inhibitor policy in a managed care population. 1997;Sep/Oct:548-53.

- Comparative cost-effectiveness of bile acid sequestering resins, HMG Co-A reductase inhibitors, and their combination in patients with hypercholesterolemia. 1995;Nov/Dec:188-92.

\section{Disease Management-Hypertension}

- Evaluation of initial drug selection for newly medicated hypertensives at the Westinghouse Electric Corporation. 1999;Nov/Dec:505-09.

- The clinical and economic implications of drug utilization patterns in the treatment of hypertension with ACE inhibitors and calcium channel blockers in a managed care setting. 1998;Mar/Apr:194-202.

- Trends in the treatment of hypertension within managed care organizations: a national survey of HMO pharmacy directors. 1997;May/Jun: 317-22.

- Evaluating health-related quality of life in three disease management areas: asthma, diabetes, and hypertension. 1996;Jul/Aug:408-13.

\section{Disease Management-Multiple Sclerosis}

- Paying for value in the management of multiple sclerosis. 2002;Nov/Dec:520.

\section{Disease Management-Obesity}

- The efficacy and safety of anorexiant medication in the treatment of obesity: implications for managed care formularies. 1998; Jul/Aug: 422-28.

- A cost-effective analysis of appetite suppressants for obesity treatment in a managed care organization. 1998;May/Jun:293-300.

\section{Disease Management-0steoporosis}

- Prevention and treatment of osteoporosis in managed care settings. 2002;Jan/Feb:58-65.

- Alendronate use among 812 women: prevalence of gastrointestinal complaints, noncompliance with patient instructions, and discontinuation. 1998;Sep/Oct:488-92.

\section{Disease Management-0titis Media and Infectious Disease}

- Evaluation of a rule-based program to describe antibiotic utilization for otitis media among three medical plans. 1999;May/Jun:232-40.

- Medication outcomes assessment of community-acquired infections. 1999;Mar/Apr:122-26.

- Fluoroquinolone-use evaluation by acute cystitis. 1996;Sep/Oct:564-68.

\section{Disease Management—Seizure Disorders}

- The cost of treating seizure patients in a managed care organization. 1999;Jul/Aug:351-56.

\section{Disease Pathology}

- Influenza: a practical review. 2000;May/Jun:247-48.

\section{Dose Optimization}

- Dose optimization: an opportunity for pharmacy administrative services. 2002;Mar/Apr:81.

- Dose-optimization intervention yields significant drug cost savings. 2002;Mar/Apr:146-51.

\section{Drug Benefit Management-Benchmarks and Measures}

- Searching for drug benefit benchmarks - cost per day of therapy. 2002;Jan/Feb:54-55.

- The use of economic models in managed care pharmacy decisions. 1998;Jan/Feb:42-50.

\section{Drug Benefit Management-Efficiency}

- Tablet splitting to improve the value-for-money equation in cholesterol management. 2002; Nov/Dec:519.

- Effects of a tablet-splitting program in patients taking HMG-CoA reductase inhibitors: analysis of clinical effects, patient satisfaction, compliance, and cost avoidance. 2002;Nov/Dec:453-58. 
- A model for comparing unnecessary costs associated with various prescription fill-quantity policies: illustration using VA data. 2001;Sep/ Oct:386-90.

- A model to estimate drug plan cost savings from a trial prescription program. 2001;Sep/Oct:391-401.

- The impact of a telephone care pharmacy program on health care resource utilization. 2000;May/Jun:217-21.

- Pharmacy cost reduction imperative at United HealthCare. 1999;Jan/Feb:19-20.

- Practice guidelines, physician groups, and drug formularies. 1997;Sep/Oct:489-92.

- Maximizing generic substitution in managed care. 1996;Nov/Dec: 557-60,562-63.

- The evolution of best-in-class pharmacy management techniques. 1998;Jul/Aug:366-67,370,372-73.

- Pharmacy benefit administration options. 1996;May/Jun:272-78.

\section{Drug Benefit Management-Employee Benefits and Coverage}

- New generic and OTC drugs provide opportunities for drug benefit managers. 2002;Nov/Dec:520.

- Analysis of the movement of prescription drugs to over-the-counter status. 2002;Nov/Dec:499-508.

- Employee benefits consulting: an essential role for pharmacy. 2001;Jul/Aug:268-71.

- Employer-sponsored health care services. 2001;May/Jun:189-92.

- Pharmacy benefit managers and unique customer segments: large employers. 2000;Sep/Oct:342-44,346.

- The history, philosophy, and principles of pharmacy benefits. 1999; Nov/Dec:525-31.

- Quality-of-life drugs: framing the issue. 1999;May/Jun:185,189-90.

- Successful disease management programs for health and welfare fund union groups. 1998;May/Jun:269-70,272.

- Carve outs and pharmacy: fashion or fad? 1996;Jul/Aug:352,35455,359 .

\section{Drug Benefit Management-Patient Satisfaction, Benefit Knowledge, and Consumer Behavior}

- Measuring outcomes of 3-tier copay drug benefit plans. 2002;Nov/ Dec:522.

- Impact of multi-tiered pharmacy benefits on attitudes of plan members with chronic disease states. 2002;Nov/Dec:477-91.

- Drugs, PPOs, tiered cost-share for beneficiaries, and consumer preferences. 2002;May/Jun:177.

- Consumer preferences for types of cost containment in prescription drug programs. 2002;May/Jun:192-98.

- Patient satisfaction with and knowledge of their prescription drug coverage. 2001; Jan/Feb:34-42.

- The CIGNA Healthcare quality improvement and patient satisfaction project. 2000;Jul/Aug:312-15.

- Development of an interval-level scale to assess consumer satisfaction with prescription drug coverage. 2000;May/Jun:225-31.
- Drug-management strategies: consumers' perspectives. 2000; Mar/Apr 122-28.

- A comparison of satisfaction with mail versus traditional pharmacy services. 1997;May/Jun:327-37.

- Guide to consumers' pharmaceutical purchasing behavior. 1996;Sep/ Oct:489-90,494,498-99.

\section{Drug Benefit Management-Pharmacy Providers}

- Bargaining between community pharmacies and third-party payers: influences on bargaining outcomes. 2001;Jan/Feb:43-49.

- The pharmacy audit: what is it and are you prepared? 1999;Mar/Apr: 93-94,98

\section{Drug Benefit Management-Quantity Limits} and Prior Authorization (PA) (see also Prior Authorization)

- Managing care via prior authorization (PA) programs? 2002;Jul/Aug: 296.

- A neurologist's perspective on quantity limits. 2002;May/Jun:184.

- Triptan quantity limits. 2002;May/Jun:182-84.

- Medical and pharmacy cost and utilization outcomes of a quantity limit on 5-HTl agonists (triptans) by a managed care organization. 2001;Nov/Dec:468-75.

- Analysis of the effects of quantity limits. 2001;Sep/Oct:338,340.

- Evaluating the operational performance and financial effects of a drug prior-authorization program. 1997;Nov/Dec:699-706.

- Effect of a prior-authorization requirement on the use of nonsteroidal anti-inflammatory drugs by Medicaid patients. 1996;Mar/Apr:158-63.

- Assessment of Medicaid prior-approval policies on prescription expenditures: market-share analysis of Medicaid and cash prescriptions. 1996;Nov/Dec:651-56.

\section{Drug Benefit Management Methods-Benefit Design}

- Benefit maximums versus drug benefit needs for Medicare beneficiaries. 2002;Sep/Oct:402-03.

- Prescription use behavior among Medicare beneficiaries with capped prescription benefits. 2002;Sep/Oct:360-64

- Effects of Medicare+Choice annual maximum dollar prescription drug benefits. 2002; May/Jun:178.

- A cost analysis of four benefit strategies for managing a Cox-2 inhibitor. 2001;May/Jun:224-27.

- Three-tier copay systems and consumer-centric care. 2000;Sep/Oct: 351-53.

- Medicare-risk pharmacy benefit design: a new cost-effective approach to pharmacy management. 1997;Jan/Feb:103-04,106. 


\section{Drug Promotion and Advertising (see also Direct-to-Consumer Advertising (DTCA) )}

- Information requirements of health systems as drug purchasers: does the FDA have a role in setting evidentiary standards? 1996;Nov/Dec: 593-98.

- Health care communications agencies respond to managed care. 1998;Jan/Feb:9-12.

\section{Drug Spending, Utilization, and Cost Trends}

- Drug costs out of control—check your assumptions. 2002;Mar/Apr:81.

- Trends in managed care pharmacy: responding to changing environments. 2002;Mar/Apr:102-07.

- Too much or too little? The role of pharmaceuticals in the health care system. 1999;Jul/Aug:296-97,301-02.

- Trends in managed care pharmacy: preparing for the future. 2001;Mar/Apr:105-10

- Local area market dynamics. 1998;Mar/Apr:115-17,120.

\section{Drug Therapy and Therapeutic Selection}

- Clinical and economic impact of glatiramer acetate versus beta interferon therapy among patients with multiple sclerosis in a managed care population. 2002; Nov/Dec:469-76

- A pharmacoeconomic model comparing two long-acting treatments for overactive bladder. 2002;Sep/Oct:343-52.

- The search for better antipsychotics continues. 2002;Jul/Aug:298.

- Atypical antipsychotics and tardive dyskinesia. 2002;Jul/Aug:291-92.

- Neuroleptic drug exposure and incidence of tardive dyskinesia: a records-based case-control study. 2002;Jul/Aug:259-65.

- Ophthalmic agents and managed care. 2002;May/Jun:217-223

- An in-home Synagis program for RSV prevention in high-risk infants. 2001;Nov/Dec:476-81

- An assessment of emerging patterns of etanercept use in the treatment of rheumatoid arthritis. 2001;Jan/Feb:56-61.

- Using simple and relative difference to interpret changes in healthrelated quality-of-life scores for salmeterol, ipratropium, and placebo. 2000;Nov/Dec:483-87.

- Cost analysis of therapeutic interchange of calcium channel blockers for the treatment of hypertension: unexpected results from a conversion program. 2000;Sep/Oct:390-94.

- Outcomes analyses of the outpatient treatment of venous thromboembolic disease using the low-molecular-weight heparin enoxaparin in a managed care organization. 2000;Jul/Aug:298-304.

- Assessing the relevance of outcomes data for colony-stimulating factors. 2000;Mar/Apr:144-50.

- Economic assessment of the relationship between disease exacerbations and the cost of multiple sclerosis. 2000;Jan/Feb:19-24.

- Criteria for the use of tramadol in adult patients: medication-use evaluation guidelines. 1999;Nov/Dec:492-97.
- Calcium channel blockers and angiotensin-converting enzyme inhibitors for hypertension in a multimarket managed care organization. 1999; Nov/Dec:537-40.

- Safety and efficacy of a mandatory formulary switch from nifedipine GITS to amlodipine. 1999;May/Jun:225-29.

- Evaluation of blood pressure and adverse effects in patients converted from lisinopril to benazepril. 1999;Jan/Feb:52-54.

- The NTI debate. 1998;May/Jun:289-90.

- Human growth hormone: ethical and economic considerations of use and misuse. 1997;Jul/Aug:448-52.

- Outcomes and cost savings of an ACE inhibitor therapeutic interchange. 1997;Mar/Apr:219-23.

- Physicians' perspectives of a therapeutic conversion with a staff-model HMO. 1997;Jan/Feb:55-56,65.

- Retrospective analysis of formulary transition at large metropolitan HMO: nifedipine GITS to felodipine ER. 1996;Nov/Dec:642-46.

\section{Drug Therapy-Natural Products}

- Managing natural products. 2001;Sep/Oct:414-19.

- Top-selling herbal supplements. 1999;Jul/Aug:357-66.

\section{Drug Utilization Review (DUR) or Drug Utilization Management}

- Gabapentin and indications of appropriate use. 2002:Jul/Aug:293-94

- Gabapentin use in a managed Medicaid population. 2002;ul/Aug: 266-71.

- DUR messages — better data needed for making better decisions. 2002;May/Jun:178-79.

- Better data for making better decisions: finger-pointing or useful drug use review. 2002;May/Jun:208-10.

- High frequency of itraconazole prescriptions with potentially interacting medications in a large health care plan. 2002;May/Jun:199203.

- Potentially inappropriate medication use in a Medicare managed care population: association with higher costs and utilization. 2001;Sep/ Oct:407-13.

- A provincial program in Nova Scotia to decrease the use of wet nebulization respiratory medications. 2000;Nov/Dec:457-58,460-61,464.

- Medicaid drug utilization review and managed care: the perspectives and experiences of state program directors. 2000;Mar/Apr:131-36.

- Incidence of anxiolytic/hypnotic therapy and its relationship to duration of antidepressant therapy in a national managed care organization. 2000;Mar/Apr:138-42.

- Evaluation of online prospective DUR programs in community pharmacy practice. 2000;Jan/Feb:27-32.

- The pharmacist's assessment of second generation online prospective drug utilization review. 1998;Mar/Apr:183-191.

\section{Ethics}

- A question of ethics. 2001;Nov/Dec:436.

- Ethics and the use of drug formularies. 1996;Mar/Apr:76,78,81-82. 


\section{Formulary Management-Methods and Effects- Pharmacoeconomics}

- Economic evaluation of citalopram use and expenditures among recipients in the Texas Medicaid program.2002;Nov/Dec:494-500.

- Exploring the methodological challenges of investigating comparison groups with different underlying characteristics: a case study. 2002;Sep/Oct:353-59.

- AMCP guidance for submission of clinical and economic evaluation data to support formulary listing in U.S. health plans and pharmacy benefits management organizations. 2001;Jul/Aug:272-82.

- The effect of a closed formulary in the face of real-life enrollment and disenrollment patterns. 2000;Jul/Aug:293-97.

- The pros and cons of formularies. 2000;May/Jun:203-07.

- The role of pharmacoeconomic information in the formulary decision-making process. 2000;Mar/Apr:108,113-14,117-18,121.

- Outcome analysis of a formulary transition from nifedipine to felodipine at a Veterans Affairs Medical Center. 1999;Sep/Oct:425-28.

- The impact of a therapeutic interchange program in a managed care organization. 1999;Sep/Oct:438-41.

- Managed care formularies in the United States.1999;Jul/Aug:28992,295.

- A predictive cost analysis model for estimating formulary impact of new products in managed care. 1996;Nov/Dec:585-90.

- Formulary management by an on-site school of pharmacy faculty member in a Medicaid managed care organization. 1998;Jul/Aug:407-10.

- Innovative drug formulary management through computer-assisted protocols. 1998;May/Jun:246-47,251-52.

- DOD's Pharmacoeconomic Center: translating research into good patient care practices. 1997;Nov/Dec:662-64,666.

- Applications of pharmacoeconomics for managed care pharmacy. 1997;Nov/Dec:720-26.

- Managing the pharmacy benefit: the formulary system. 1997;Sep/ Oct:565-73.

- Drug formularies: real opportunities to improve MCO efficiency. 1997; May/Jun:254,375-76.

- Pharmacoeconomic analysis of hormone replacement therapyimplications for managed care. 1997;Mar/Apr:200-09.

- Using outcomes as a tool to evaluate formulary selection decisions: hypercholesterolemia as a case example. 1996;Jul/Aug:396-404.

- Development of a community-based formulary comparison instrument. 1995;Nov/Dec:211.

- Pharmacoeconomic evaluations: guidelines for drug purchasers. 1996;Nov/Dec:671-77.

\section{Formulary Management-P \& T Committees}

- The pharmacy and therapeutics committee competition goes national: building toward Tampa and beyond. 2001;Nov/Dec:448-51.

- Pharmacy \& therapeutics committees: a mock meeting at AMCP. 1996; Jul/Aug:380,383-84.

\section{Health Care Delivery}

- Pharmacy: looking back to see the future. 1998;Sep/Oct:454-55,45960,462 .

- International markets offer new opportunities for MCOs and PBMs. 1997;Jul/Aug:403-04,409-10.

- Integration takes managed care in different directions: horizontal, vertical, and beyond. 1997;May/Jun:260,263-64.

- Looking back: failed health care reform put managed care on the map. 1997;Mar/Apr:159,160,163.

- Indian Health Service: paving the way for pharmaceutical care. 1997; Jan/Feb:36,41-43.

- Alternative medicine in managed care pharmacy. 1997;Jan/Feb:7780,83-86.

- Rocky Mountain HMO. 1996;Sep/Oct:500,502-04,507.

- Veterans Affairs Health System: embracing new challenges, new changes. 1996;Mar/Apr:111-12,117-18.

- Managed care cautiously embraces complementary medicine. 1996;Nov/Dec:626,631-33.

- While health care evolves, antitrust law endures. 1996;Nov/Dec:67986.

\section{Health Care Quality Improvement}

- Information technology to cross the quality chasm. 2002;Sep/Oct: 401-02.

- Quality improvement opportunities in health care-making it easy to do it right. 2002;Sep/Oct:394-99.

- Quality measures: looking in all the wrong places. 2001;Mar/Apr:88.

- Medical and medication errors: a partial summary of reports by the Institute of Medicine and the quality interagency coordination task force. 2001;Jan/Feb:62-68.

- Developing disease state management in the United Kingdom: an obviously American conjecture finds export opportunities abroad. 1998;May/Jun:275-76,279-83,287.

- Managed care and the quest for quality measures. 1997;May/Jun: 255,258-89.

- How to evaluate disease state management programs. 1997;May/Jun: 270,273-74,277-78

- Innovations in quality improvement: managed care leads the way. 1996;Jan/Feb:20,22,24,27-28.

- Disease state management. 1995;Sep/Oct:128-33.

- Successful CQI-based programs in a group-model managed care setting. 1995;Sep/Oct:134,137.

- Quality assessment and quality assurance of pharmacy services. 1995;Jul/Aug:40-51

\section{Health Care Spending and Health Economics}

- Is there no prescription to decrease health care outlays in the face of an aging population? 2000;Nov/Dec:450-51.

- Health economics II: some unique aspects of health economics. 2000;Mar/Apr:173-78. 
- Health economics I: basic economic principles. Evaluation of online prospective DUR programs in community pharmacy practice. 2000;Jan/Feb:43-50.

\section{Health Insurance and Health Care Finance}

- The Health Insurance Portability and Accountability Act of 1996: the issue of portable health care coverage. 1999;Mar/Apr:81,85-88.

- Direct contracting: the next purchaser strategy. 1996;Jan/Feb:11$12,14,16$.

\section{Institutional Managed Care}

- Managed pharmaceutical care within a criminal justice system. 2001;May/Jun:182.

\section{Internet Pharmacy}

- Concern about foreign-source pharmacy Internet providers. 2001;Sep/Oct:335-36.

- The Internet and PBMs: new business model or business as usual? 2000;Mar/Apr:102,105-07.

- With the click of a mouse. Evaluation of online prospective DUR programs in community pharmacy practice. 2000;Jan/Feb:73.

\section{Lifestyle Drugs}

- Enhancing life or eradication ugliness?: lifestyle drugs. 2002;Jan/Feb: 15-16,19-20.

\section{Managed Care Pharmacy Practice}

- John Ogden talks about managed care in the Veterans Administration. 2002;Mar/Apr:91-93.

- The value of managed care pharmacy in an IPA setting. 2001; Nov/Dec:438-39.

- Innovative managed care pharmacy practice. 2001;Mar/Apr:90-92; 2001;Jan/Feb:8,9.

- Career changes in managed care pharmacy. 2000; May/Jun:208,10,15.

- Managed care and the pharmacy profession revisited. 1999;Mar/ Apr:78.

- Advancing outcomes research in managed care pharmacy: a call to action. 1998;May/Jun:257-58,261-63,266-67.

- The importance of communication skills for the managed care pharmacist. 1998;Mar/Apr:102.

- The evolution of pharmaceutical care into managed care environments. 1998;Jan/Feb:55-58.

- The changing face of managed care pharmacy and the role of PBMs. 1997;Sep/Oct:494,497-98.

- Managed care pharmacists: leading the way for a new millennium. 1997;Jul/Aug:383-85,388.

- Managed care pharmacy: leading pharmaceutical care integration forward. 1997;Mar/Apr:139,141-42,145-47.
- Consultant pharmacy and managed care: a partnership for the future. 1997;Mar/Apr:164,167-69.

- Internal marketing: essential challenge for managed care pharmacy. 1996;Sep/Oct:473-74,479-80.

- Prescription solutions: managing pharmacy care through flexibility and innovation. 1996;Jul/Aug:385-86,389-90,395.

- Harvard Pilgrim Health Care: a new partnership in promoting pharmaceutical care. 1996;May/Jun:249-50,252,254.

- Blue Cross and Blue Shield: making pharmaceutical care a key component of managed care. 1996;Jan/Feb:33-34,36,38.

- CIGNA HealthCare: a leader in pharmacy re-engineering. 1995; Nov/Dec:174-75,178,180.

- Professional opportunities in managed care pharmacy. 1995;Sep/Oct: 80,82,86-87.

- Systemed: the future in PBMs. 1995;Sep/Oct:109-10,113-14.

- Issues and concerns of managed care pharmacy directors: results of a national survey. 1995;Sep/Oct:116-20.

- Kaiser Permanente medical care program. 1995;Jul/Aug:26-28,30.

- Group Health Cooperative. 1996;Nov/Dec:634-36,639-40.

\section{Managed Health Care}

- Examining the managed health care continuum. 1997;Sep/Oct:51112,515-16,518.

- Physician-management companies: ready to make their move in managed care. 1996;Mar/Apr:95-96,98,100,106-07.

\section{Manpower and Job Satisfaction}

- How many pharmacists are in our future? The Bureau of Health Professions projects supply to 2020. 2000;Nov/Dec:474-82.

- Charting the demand for pharmacists in the managed care era. 1999;Jul/Aug:324-28.

- Burnout in a sample of HMO pharmacists using the Maslach Burnout Inventory. 1998;Sep/Oct:495-503.

\section{Medicaid}

- State-by-state look at Medicaid retail pharmacy delivery: trials and triumphs. 1996;Nov/Dec:546-47,551-52,554.

\section{Medicare (see also Drug Benefit Management Methods- Benefit Design)}

- Medicare and managed care update 2000. 2000; Nov/Dec: 466,468, 470,472 .

- Prescription coverage options for Medicare beneficiaries. 1999; May/ Jun:250-54.

- Medicare and managed care: emerging partnerships. 1998; Mar/Apr: 105,108-10,112

- Overview of Medicare for managed care professionals. 1996; Mar/ Apr:165-72. 


\section{Pain Management}

- It's a pain. 1999;Nov/Dec:558

\section{Pharmaceutical Industry}

- India's pharmaceutical industry: a growing influential force in the world pharmaceutical market. 2002;May/Jun:211-15.

- International movement of Japan's pharmaceutical industry: reform of Japanese health policies, Part III. 1998;Nov/Dec:567-68,571-72,555$57,580,582-83$.

- International movement of Japan's pharmaceutical industry: reform of Japanese health policy, Part II. 1998;Mar/Apr:123-24,127-28,130,13537.

- International movement of Japan's pharmaceutical industry: health policy reform. 1997;Nov/Dec:667-68,671-74.

- Pharmaceutical privatization and reform program in Kazakhstan 1997:Jul/Aug:415-16,418-19,422.

- The drug approval process in the U.S., Europe, and Japan. 1997;Jul/Aug:459-65.

- Manufacturer-provided alliances: case studies of the nature of and prospects for several model arrangements. 1996; May/Jun:227,231,23536,239.

- U.S. pharmaceutical firm prospects within the People's Republic of China. 1996;May/Jun:240-42,245-48.

- Industry partnerships: disease management programs flourish. 1995; Nov/Dec:164,166,170-72.

- Evaluating the pharmaceutical industry interface with managed care. 1995;Jul/Aug:35-39.

\section{Pharmacogenomics}

- Drug therapy customized to individual patients. 2002;Jul/Aug:296-97.

- Evaluating the potential impact of pharmacogenomics on ADRs. 2002;Jul/Aug:285-90.

- Health care professionals' perceptions of the role of pharmacogenomic data. 2002;Jul/Aug:278-84.

\section{Pharmacy Education}

- Managed care and the University of Texas College of Pharmacy. 2001;Nov/Dec:490

- University of Michigan College of Pharmacy and managed care partner to enhance drug therapy. 2001;Sep/Oct:345-46.

- An inside look at the benefits of a student pharmacy and therapeutics (P \& T) committee competition from the University of Illinois at Chicago. 2001;Jul/Aug:259-60.

- Managed care concepts prominently featured in innovative management programs at Duquesne University. 2001;Mar/Apr:94,96.

- Managed care teaching and research in South Dakota. 2001; Jan/Feb:10,11.

- Synergy between the University of Louisiana at Monroe and the Louisiana Drug Utilization Review Board. 2000;Sep/Oct:420.
- Virginia Commonwealth initiates combined graduate programs 2000;Jul/Aug:327-28.

- College offers certified managed care pharmacist program. 2000 May/Jun:262-63.

- The University of Maryland's Center on Drugs and Public Policy. 2000;Mar/Apr:184-85.

- Teaching managed care pharmacy and disease management in Canada. Evaluation of online prospective DUR programs in community pharmacy practice. 2000;Jan/Feb:71-72

- Managed care pharmacy practice at the Texas Tech University Health Sciences Center School of Pharmacy. 1999;Nov/Dec:556-57.

- Description of a formal affiliation between a school of pharmacy and a managed care organization. 1999;Sep/Oct:433-37.

- Students gain exposure to managed care principles at a new school of pharmacy. 1999;Jul/Aug:371.

- Improving efficiency and effectiveness in managed care: ongoing efforts at the University of New Mexico College of Pharmacy. 1999;Mar/Apr:111.

- Pharmacy internship offers real-world exposure to managed care pharmacy practice. 1996;Nov/Dec:605-06.

- Cooperative learning in a required outcomes assessment course. 1998;Jul/Aug:431-32.

- First managed care pharmacy course at the University of Illinois at Chicago. 1998;Jan/Feb:80-81.

- Draft criteria for residency programs in managed care pharmacy. 1997;May/Jun:363-64,366,368,371

- Internship takes classroom into the "real world." 1997;Mar/Apr: 234,241 .

- Linking the ivory tower and real-world practice: building a synergy bridge in managed care pharmacy. 1997;Jan/Feb:107-08,110.

- New degree program at Ole Miss: B.S. in pharmaceutical sciences/management major. 1997;Jan/Feb:112-113.

- Managed care pharmacy at the St. Louis College of Pharmacy. 1996;Jul/Aug:439,442.

- Managed care pharmacy education at the University of Washington School of Pharmacy. 1996;May/Jun:319-20.

- Managed care pharmacy curriculum in pharmacy schools: the Samford University perspective. 1996;May/Jun:320.

- Managed care pharmacy education at MCP. 1996;Jan/Feb:53.

\section{Physician Education-Intervention-Academic Detailing}

- Selection bias in physician education-intervention programs 2002;Mar/Apr:82.

- Physician education-intervention influenced prescribing for otitis media. 2002;Mar/Apr:141-45.

- Effect of physician profiles and academic detailing on cost and utilization of selective serotonin reuptake inhibitors. 2002;Jan/Feb:23-31.

- Driving market share in an integrated health system without therapeutic interchange. 2001;jul/Aug:283-86.

- Effect of provider education and feedback on antihypertensive prescribing in a department of Veterans Affairs primary care clinic 2000;Jul/Aug:307-10. 
- Academic detailing to influence prescribing. 1997;Nov/Dec:63133,637-38.

- Academic detailing: methods and success stories in IPA-model HMOs. 1996;Sep/Oct:586-88,593-94,596.

- Academic detailing: what's in a name? 1996;Mar/Apr:88-90.

- Effectiveness of academic detailing in the managed care environment: improving prescribing of lipid-lowering agents. 1996;Mar/Apr:148-57.

- UIC students mobilize first student chapter of AMCP. 1995;Nov/Dec:185-86

\section{Population Health—Interventions and Prevention of ADEs}

- An employee influenza initiative in a large university managed care setting. 2001;May/Jun:219-23.

- Who bears responsibility for glucocorticoid-exposed patients in a large health maintenance organization? 2001;May/Jun:228-32.

- Public health, managed care, and pharmacy: an evolving trifecta. 2001;Jan/Feb:12,14-16.

\section{Prior Authorization (PA)}

- Prior authorization programs: a critical review of the literature. 2001;Jul/Aug:297-302

\section{Privacy of Health Information}

- Privacy just took on a whole new meaning: what HIPAA means to pharmacists. 2001;Sep/Oct:342.

- Employer access to employee prescription records: dilemmas for pharmacists. 1997;Sep/Oct:504-05,508.

\section{Quality Assurance}

- Credentialing in pharmacy. 2001;Jan/Feb:22-27,30-31.

\section{Research Methods (see also Survey Methods)}

- Single-patient trial (SPT) method-substitute for expert opinion? 2002;Nov/Dec:519.

- Statistical significance versus practical significance. 2002;Sep/Oct: 404.

- Conjoint analysis in pharmaceutical research. 2002;May/Jun:206-08.

- Researching managed care pharmacy using Internet searches. 2001;May/Jun:201-04, 213.

- Research methodology: some statistical considerations. 1996;Nov/Dec: 617-21.

- Research methodology: designing a research study. 1998;Sep/Oct:50414.

- Research methodology: hypotheses, measurement, reliability, and validity. 1998;Jul/Aug:382-88.

- The vital role of pharmacy benefit management firms in health services research. 1998;Jan/Feb:23-24,26-28
- Calculating risks and number-needed-to-treat: a method of data interpretation. 1997;Mar/Apr:179-83.

- Epidemiological techniques. 1997;Jan/Feb:30-32,35.

- Method is everything: evaluating results by study design. 1997;Jan/Feb:66-68,71-72,75-76.

- Measuring quality of life: a primer for managed care pharmacists. 1996;Jul/Aug:415-22.

- Research in managed care: outcomes research in disease prevention and management. 1996;May/Jun:212,214,216,221-22.

- Interface between pharmacoepidemiology and pharmacoeconomics in managed care pharmacy. 1996;May/Jun:282-89.

- Drug-related morbidity and mortality: a cost-of-illness model. 1996;Jan/Feb:39-47

- Outcomes research, pharmacoeconomics, and the pharmaceutical industry. 1996;Jan/Feb:48-52.

\section{Safety-Health Care Worker}

- New standards to prevent needle-stick injury. 2001;Sep/Oct:349-52.

\section{Safety-Patient Care (see also Drug Utilization Review (DUR))}

\section{Specialty Pharmacy}

- The emergence of specialty pharmacy. 2000;Jul/Aug:280-84.

\section{Survey Methods (see also Research Methods)}

- Constructing mail survey questionnaires to maximize the rates of return and assure the validity and reliability of responses. 2002;May/Jun:225-31.

- Implementing mail survey questionnaires. 2002;Mar/Apr:157-61.

- Going to the source: a guide to using surveys in health care research. 1999;Mar/Apr:150-59.

\section{Technology-Automation}

- Automated dispensing technologies: effect on managed care. 1995;Sep/Oct:212-17.

\section{Technology-Education and Information}

- Use of technology throughout the curriculum. 2002;Mar/Apr:86.

- Critical evaluation of web sites: an example in osteoporosis. 2000;Jul/Aug:316-22.

- Adopting knowledge technology to "manage" care: issues and status of physician use. Evaluation of online prospective DUR programs in community pharmacy practice. 2000;Jan/Feb:35-41.

- The Internet: changing the managed pharmaceutical care environment. 1999;Sep/Oct:387-88, 390,392

- The year 2000 in pharmacy-business as usual or disaster in progress? 1999;Jul/Aug:305,308-10. 
- Technology and automation update. 1998;May/Jun:345-50.

- Automation aids prescription processing — but professional judgment remains indispensable. 1995;Sep/Oct:90,93-95.

- Gaining links: health information networks arise with integration challenges. 1995;Sep/Oct:96-98,100.

\section{Technology-Electronic Prescribing}

- Extent of electronic prescribing implementation as perceived by MCO pharmacy managers. 2002:Jan/Feb:41-47.

- Electronic prescribing in ambulatory care: a market primer and implications for managed care pharmacy. 2001;Mar/Apr:115-20.

- Connecting physicians to pharmacies—and patients. 1998;Sep/ Oct: 473-74,477.

- Electronic prescribing: the next revolution in pharmacy? 1998; Jan/ Feb:35-36,39

\section{Therapeutic Interchange-Therapeutic Selection}

- Utilization of pharmacy claims data to evaluate therapeutic interchange programs. 1999;Jul/Aug:331-34.

- Risk-taking propensity and drug product selection behavior of pharmacists. 1997;Jul/Aug:439-43.

\section{Value of Pharmacotherapy}

- RxHealthValue offers three recommendations and cost research. 2001;Jan/Feb:17-20.

\section{Women's Health}

- Women's health: issues and opportunities for managed care pharmacy. 2001;Jul/Aug:263-67.

- Estimating the relative cost effectiveness of four contraceptive methods in the prevention of unwanted pregnancies within the Department of Defense active-duty women. 1999;Mar/Apr:131-36. 